\title{
Effectiveness of Rehabilitation Programmes in the Nigerian Prisons: A Study of Perception of Inmates in Enugu Prison
}

\author{
Uche, ljeoma B. \\ Department of Social Work, University of Nigeria, Nsukka - Nigeria \\ Email: blessijcarol@gmail.com \\ Uche, Okala A. \\ Department of Social Work, University of Nigeria, Nsukka - Nigeria \\ Email: ucheokalaa@gmail.com \\ Ezumah, Nkoli N. \\ Department of Sociology/Anthropology, University of Nigeria, Nsukka- Nigeria \\ Email: ezumahnk@yahoo.com \\ Ebue, Malachy 0. \\ Department of Social Work, University of Nigeria, Nsukka - Nigeria \\ Email: archy_okey88@gmail.com \\ Okafor, Agnes E. \\ Department of Social Work, University of Nigeria, Nsukka- Nigeria \\ Email: agnes.okafor@unn.edu.ng

\section{Ezegbe, Bernedeth Nkiruka (Ph.D)} \\ Department of Social Science Education, University of Nigeria, Nsukka \\ Email: bernedeth.ezegbe@unn.edu.ng
}

\section{Doi:10.5901/mjss.2015.v6n4s2p164}

\section{Abstract}

The objective of the study was to find out the prison inmates' perception of the effectiveness of rehabilitation programmes in the Nigerian prisons service with reference to Enugu prison. The study adopted the cross-sectional survey design. A total of one hundred and forty five (145) inmates comprised the target of the study. Questionnaire was the instrument used for data collection. The Statistical Package for Social Sciences (SPSS), frequency tables and percentages (\%) were employed in the data analysis. The result showed that rehabilitation programmes in the prisons have not achieved much. It was also discovered that the duration of service for the inmates does not make the inmates to be actively involved in rehabilitation programmes. Majority of the respondents agreed that lack of fund/inadequate funding was the major hindrance to the programmes. It is recommended that social workers, philanthropists should contribute in ensuring that adequate facilities are provided to enhance the effectiveness of the rehabilitation programmes.

Keywords: Effectiveness, perception, prison inmates, rehabilitation, rehabilitation programmes.

\section{Introduction}

The aim of imprisonment according to section 2(4) of the Nigerian Prison Act (1972) is to endeavour to identify the reason for anti- social behaviour of the offenders; to train, rehabilitate and reform them to be good and useful citizens. It is therefore expected that the recidivism will decrease if the objective of imprisonment is achieved by planning and providing proper rehabilitation of prisoners. This will enable them to be law abiding citizens of the society and engage in productive 
activities for their daily living on release from prison.

Colonial prisons in Nigeria were not designed for reformation or rehabilitation rather prisons were intended to be punitive. Hence, prisoners were used mainly for public works and other jobs for the colonial administrators as a form of punishment (Investigating Human Right, n:d; 176-184). At the end of the Second World War (1939-1945), there was a remarkable shift in penal philosophy, particularly in colonial territories. The emphasis was no longer primarily on the punishment of criminals but there was also concern for their reformation and rehabilitation (Igbo, 2007). Officially, it is claimed that the role of the Nigerian prison services is tripartite in nature. Firstly, the service is responsible for the safe custody of persons legally interned. Secondly, it provides treatment to them, and thirdly, it seeks to rehabilitate them. The philosophy of the Nigerian prison service is that treatment and rehabilitation of offenders can be achieved through carefully designed and well-articulated administrative, reformative and rehabilitative programmes aimed at inculcating discipline, respect for the law and order and regard for the dignity of honest labour (Nigerian Prison Services, 2009).

A prisoner without adequate rehabilitation opportunity through skills training and capacity building usually returns to the society which has incarcerated him or her as a hardened enemy of that society. Such an ex-convict is often full of desire for vengeance because he or she sees himself or herself as victimized rather than corrected. In addition, such an ex-convict is likely to do more harm than good to a society invariably perceived as an oppressive system. This condition explains to a very great extent why many Nigerian ex-prisoners end up as recidivists (Ugwuoke, 1994).

The rehabilitation of prison inmates should begin from the very day they are admitted into the prison to the day they are discharged (Igbo, 2007). This is to ensure that they utilize the skills they acquired in the course of rehabilitation to live a law abiding life in the society. There are a number of programmes in place meant to divert offenders from crime to useful pursuits that make crime unattractive or condemnable such as moral or religious institutions, education, vocational training etc. Based on the fact that efforts of the prisons in equipping the inmates with vocational skills are faced with various problems, questions as to whether the prisons are actually rehabilitating convicts, the effectiveness of these rehabilitation programmes or whether there is an existing conflict between the punitive ideas of imprisonment inherited from the colonialism and the need for rehabilitation are issues of concern. The above necessitated the interest of this study of Enugu prison; and examined the inmates' perception of the effectiveness of rehabilitation programmes.

\section{Statement of the Problem}

Despite the noble objectives of reformation, rehabilitation and reintegration which the Nigerian prison system embarks on to ensure that criminals become changed persons, the realization of this objective has been obstructed by certain factors. (Ayodele, 1993) asserted that the rate at which ex-convicts are returning to jail is alarming. Reformation of prisoners has not been effective as every year criminals who become more hardened and deadly are released as against changed individuals expected by the society. Ayodele further stated that prisons have in modern times become training ground and school for a new category of criminals and patterns of crime unknown to the society. In addition, (Civil Liberty Organization, 1993) reported that the prison is just where one learns one or two mistakes that led to one being arrested, so that inmates get smarter by sharing experience with more learned colleagues. In line with this, (Adelaja, 2009) noted that prisoners left unoccupied with constructive and positive activities are likely to perfect their criminal activities through the learning of new tricks from other inmates.

The claim that Nigerian prisons are engaged in carefully designed and well articulated reformative and rehabilitative programmes aimed at inculcating discipline and respect among convicts (Nigerian Prison Services, 2009) is not supported by the rule of retributive punishment which prison administrators have continued to enforce. Adjustment of discharged prisoners in Nigeria has become a huge problem because the society has come to view such discharged prisoners as social misfits who are not amenable to corrections. Such discharged prisoners are therefore, stigmatized and treated as social pariahs. This rejection by the society sometimes forces them back to crime. In addition, (Latessa \& Allen, 1999) expressed the view that the inmate who has served a longer amount of time in prison has had his tendencies toward criminality strengthened and is therefore more likely to recidivate than the inmate who has served a lesser amount time. They argued that prisons are like schools of crime where one learns more crime from the peers (inmates).

(Ugwuoke, 2000) observed that the Nigerian penal institutions are saddled with the function of performing contradictory roles. On the one hand, the prisons are expected to reform and rehabilitate inmates; while on the other hand, they are equally expected to perform the retributive function of ensuring that the inmates are adequately punished for their crimes. Despite the fact that the Nigerian prisons service today, is assigned the onerous responsibility of ensuring the safe custody of offenders as well as their reformation and rehabilitation (Nigerian prisons services, 2009), huge part of the prisons' activities favour retribution. In reaction to this, (Ugwuoke, 2000) affirmed that the Nigerian prisons service is in a dilemma because rehabilitation and retribution practices are not compatible. It is to this effect that 
one wonders whether the prisons are actually rehabilitating convicts or are still depending on punitive practices. To this end, Nigerian prisons find it difficult to perform their statutory functions which include the custody of offenders as well as their reformation and rehabilitation (NPS, Annual Report, 2000).

In developed countries like America, the inmates are engaged in vocations such as shoe making, carpentry, weaving and tailoring among others. There are institutional programmes which include a variety of activities, all of which can have an impact either directly or indirectly on the rehabilitation of offenders and their successful reintegration into the community after release. These programmes include among others recreational services(these have medical, humanitarian, social-psychological motives; they are structured to ease the pressure of confinement, making inmates more receptive to rehabilitation and less depressed, hostile and asocial), religious services(religious counseling and worship services), work services(related to the successful economic functioning of the institution and rehabilitative of offenders), academic and vocational services(this attempts to provide inmates with the skills necessary for adequate employment after release) and medical services(hospitals, full time physician or nurse, provision of drugs, the medical unit is also responsible for monitoring sanitary conditions and inmates dietary needs) (Inciardi, 2009).

In Nigeria, the welfare of prisoners and prison officials is nothing to write home about. The prevailing poor conditions (poor feeding, toilets, beddings among others) which the prison officials and inmates are subjected to have provided a fertile ground for revolt. Indeed, most of the incidents of jailbreak that have been recorded in the country were occasioned by the unbearable inhuman situation in our prisons (Udutchay, 2010). Some prison officials sometimes incite inmates to involve themselves in jailbreak because of the prevailing conditions.

Prison inmates that embrace rehabilitation during their period of incarceration acquire skills that provide them with services, opportunities and employment on discharge. The prison authorities with the efforts of the government have provided various rehabilitation programmes in various prisons. These programmes range from adult literacy, tailoring, welding, carpentry, and farming among others. The study therefore was an effort to ascertain inmates' perception of effectiveness of rehabilitation programmes in Enugu prison.

\section{Objectives of the Study}

The general objective of this study was to examine the inmates' perception of the effectiveness of rehabilitation programmes in the Nigerian prisons with reference to Enugu prison.

The specific objectives are as follows:

1. To identify rehabilitation programmes provided for the prison inmates.

2. To examine the duration of rehabilitation programmes in the prison.

3. To identify the problems with rehabilitation of prisoners.

4. To determine the relevance of the rehabilitation programmes for prison inmates.

\section{Theoretical Orientation}

The rehabilitation theory was adopted as the basis for the theoretical framework of this study. According to Packer as cited in Dambazau (2007), rehabilitation theory posits that offender should be treated as an individual whose special needs and problems must be known in order to enable prison officials deal effectively with him. They also argued that one cannot inflict a severe punishment or inhuman treatment to inmates in the prison and expect them to be reformed and reintegrate themselves into the society upon release. Although it is important to inflict punishment on those persons who breech the law, so as to maintain social order, the importance of rehabilitation is also given priority as it is the only assured way of ensuring that offenders do not return to crime particularly since they have acquired skills that will help them engage in productive activities upon release (Wikipedia, 2009). The theory of rehabilitation therefore, seeks to reduce recidivism because it believes that through retraining programmes for offenders, a more purposeful life would be guaranteed to ex-convicts.

Rehabilitation theory is the most valuable ideological justification for punishment. It promotes the humanizing belief in the notion that offenders can be saved and not simply punished. It recognizes the reality of social inequity. To say that some offenders need help to be rehabilitated is to accept the idea that circumstances can constrain, if not compel and lead to criminality; it admits that we can help persons who have been overcome by their circumstances. It rejects the idea that individuals, regardless of their position in the social order, exercise equal freedom in deciding whether to commit crime, and should be punished equally according to their offence irrespective of their social background (Tan, 2008).

Furthermore, this theory is relevant to the study as it tries to establish the justification or rationale behind the treatment of the convict by changing the attitude and behaviour of criminals so that they will be able to choose lawful 
means, in satisfying their needs (Dinitz \& Dine, 1989). This theory emphasizes the need to retrain the convict so that he can live a lawful and independent life which upon release. It advocates that vocational training be designed to transform convicts' life styles through the vigorous application of discipline, education, work and other relevant programmes.

\section{Materials and Methods}

\subsection{Study area}

Enugu State was created in 1991. Enugu State has a population of 3,257,298 with 17 Local Government Areas (NPC, 2006). Enugu State has a total of 4 prisons with the maximum prison at Enugu the State capital. These include Enugu Prison; Ibite Olo prison (farm centre); Nsukka prison and Oji River prison. The study was carried out in Enugu prison.

The purposive sampling technique was adopted in the study. The convicted inmates of the prison under study were purposively sampled for the study because they were the only prison inmates involved in rehabilitation programmes. All the convicted male and female inmates of the prison were used in the study. The Awaiting Trial Mails (ATMs) were however, excluded from the study because they do not have access to rehabilitation programmes in the Nigerian prisons. Data was collected from the respondents using questionnaire, which was other administered using two trained research assistants. The questionnaires were administered during the inmates' "open out" recreation exercise. The first part of the questionnaire contains demographic characteristics of the respondents, while the second part deals with the specific issues of the study.

\subsection{Sample}

A sample of one hundred and forty five (145) prison inmates was drawn from Enugu prison. The rationale behind the use of this number is because rehabilitation programmes are meant for the convicted mail only and these happen to be the number undergoing rehabilitation programmes as at the time of the study. The demographic characteristics of the population show that there are 129 males (89\%) and 16 females (11.0\%). The mean age of the respondents was 21 years. Most of them were married (50.0\%). $7.6 \%$ of the respondents do not have any formal education, $4.1 \%$ have Koranic education, $29.0 \%$ have primary education, $37.2 \%$ have either SSSC or GCE, $16.6 \%$ have B.Sc and above, while $5.6 \%$ specified that they have NCE/Diploma and RSA. The respondents are predominantly Christians (81.4\%). Less than half were students (35.2\%) before conviction, $24.1 \%$ were Civil servants, $14.5 \%$ were traders, (10.3\%) were unemployed, while $8.3 \%$ were farmers.

\subsection{Measures}

To understand inmates' perception of the effectiveness of rehabilitation progrmmes, the following questions were asked:

1. Does rehabilitation progrmmes exist in the prison?

2. What type of rehabilitation programmes exist for the inmates?

3. How long does rehabilitation programmes last?

4. How would you assess the rehabilitation programmes in the prison?

5. What hinders rehabilitation programmes?

6. What impact has rehabilitation programmes made in your life?

\subsection{Results}

Results from the study show that all the respondents agreed that rehabilitation programmes exist in the prison (100.0\%), that rehabilitation progrmmes cover adult literacy and carpentry (26.0\%) respectively, tailoring (18.0\%), arts/crafts and welding (15.0\%) respectively, and that the progrmmes last as long as one is in prison (93.1\%). However, majority of the respondents (62.8\%) and (31.0\%) perceived the programmes as fairly successful and not successful respectively. Moreover, the major hindrance to habilitation programmes was lack of fund/inadequate funding $(35.2 \%)$. However, majority of the respondents (85.5\%) were of the view that rehabilitation programmes have made positive impact in their lives.

The first question sought to find out the existence of rehabilitation programmes in the prison. All the respondents under study maintained that rehabilitation programmes exist in the prison. These include adult literacy, arts/crafts, carpentry, tailoring and welding. 
The second question focused on the types of rehabilitation programmes inmates were involved in. This is presented in Figure 1.

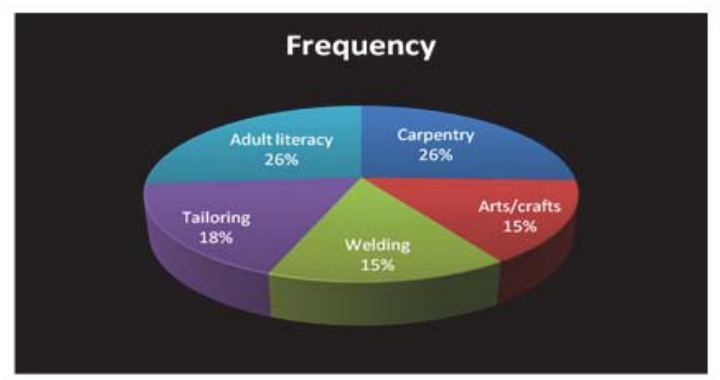

Figure 1: Types of rehabilitation programmes inmates were involved in.

Source: Field work, 2012/2013

Fig. 1 shows the types of rehabilitation programmes inmates participated in. Out of 145 prison inmates used for the study, $26.0 \%$ were involved in adult literacy and carpentry respectively, $18.0 \%$ were involved in tailoring, and $15.0 \%$ were involved in welding and arts/crafts respectively. in table 1

The third question was concerned with the duration of rehabilitation programmes in the prison. This also is shown

Table 1: Duration of rehabilitation programmes in Enugu prison

\begin{tabular}{ccc}
\hline Duration of rehabilitation programmes & Frequency & Percentage (\%) \\
\hline 6 months & 2 & 1.4 \\
12 months & 8 & 5.5 \\
As long as one is in prison & 135 & 93.1 \\
\hline Total & 145 & 100.0 \\
\hline
\end{tabular}

Source: Field work, 2012/2013

Table 1 shows that 93.1 percent of the respondents said that rehabilitation programmes last as long as one is in prison, $5.5 \%$ indicated that it last for 12 months, while the remaining 1.4\% said that they last for 6 months.

The fourth question focused on the inmates' assessment of rehabilitation programmes. Table 2 below shows their responses.

Table 2: Respondents' assessment of rehabilitation programmes in the prison.

\begin{tabular}{ccc}
\hline Responses & Frequency & Percentage \\
\hline Successful & 9 & 6.2 \\
Fairly successful & 91 & 62.8 \\
Not successful & 45 & 31.0 \\
\hline Total & 145 & 100
\end{tabular}

Source: Field work, 2012/2013

Table 2 shows that majority of the respondents (62.8\%) perceived the programmes as fairly successful, $31 \%$ perceived the programmes as not successful, while the remaining $6.2 \%$ perceived it as successful. This implies that majority of Enugu prison inmates perceived rehabilitation programmes as fairly successful.

Question number five sought to know the obstacles in implementing rehabilitation programmes. This is presented in table 3 
Table 3: Obstacles to rehabilitation

\begin{tabular}{ccc}
\hline Responses & Frequency & Percentage (\%) \\
\hline Lack of fund/inadequate funding & 51 & 35.2 \\
Lack of physical infrastructures & 27 & 18.6 \\
Poor management/Administration & 26 & 17.9 \\
Prison staff & 1 & 0.7 \\
Breakdown of equipments & 40 & 27.6 \\
\hline Total & $\mathbf{1 4 5}$ & $\mathbf{1 0 0}$ \\
\hline
\end{tabular}

Source: Field work, 2012/2013

Table 3 shows that $35.2 \%$ of respondents identified lack of fund/inadequate funding as an obstacle to rehabilitation, $27.6 \%$ respondents indicated breakdown of equipment, $18.6 \%$ said it was lack of physical infrastructures, $17.9 \%$ said it was poor management/administration, while the remaining $0.7 \%$ indicated that prison staff do not care to rehabilitate them.

The sixth question focused on the impact of rehabilitation programmes to prison inmates. This is shown in table 4.

Table 4: The impact of the rehabilitation programmes on prison inmates

\begin{tabular}{ccc}
\hline Responses & Frequency & Percentage (\%) \\
\hline Positive Impact & 124 & 85.5 \\
Negative Impact & 1 & 0.7 \\
No Impact & 20 & 13.8 \\
\hline Total & 145 & 100 \\
\hline
\end{tabular}

Source: Field work, 2012/2013

Table 4 shows that $85.5 \%$ of the respondents said that rehabilitation programmes have impacted on them positively, $13.8 \%$ of the respondents had no impact of the rehabilitation programmes, while $0.7 \%$ had negative impact of the programmes.

\section{Discussion}

The study investigated the inmates' perception of the effectiveness of rehabilitation programmes in the Nigerian prisons with reference to Enugu prison. One hundred and forty five (145) respondents were used. In the analysis, the findings showed that rehabilitation programmes exist in prison and they include carpentry, adult literacy, arts/crafts, tailoring and welding. These findings are in agreement with the observation of Inciardi (2009) that prison programmes include a variety of activities, all of which can have an impact either directly or indirectly on the rehabilitation of offenders and their successful reintegration into the community after release.

The study also showed that as long as an inmate is in the prison, he/she undergoes rehabilitation. However, the study revealed that the rehabilitation programmes have been fairly successful. The major obstacle to rehabilitation was identified as lack of fund/inadequate funding. The finding is in agreement with Prison Annual Report (2001/2002) which indicated that inadequate funding was a major constraint which hampers both rehabilitation and after care of prisoners. Furthermore, more than half of the respondents accepted that rehabilitation progrmmes have impacted positively in their lives by teaching them skills which they will utilize on release.

\section{Recommendations}

Based on the findings, the following recommendations were made:

- The prison authorities should provide earning schemes to inmates to enhance their effective reintegration and rehabilitation into the society.

- The prison should be adequately funded to acquire state of the arts equipments to enhance effective rehabilitation of inmates.

- Social workers should create awareness on the need for every convicted mail to be involved in one 
rehabilitation programme or the other.

- Rehabilitation programmes should not be left in the hands of prison officials alone. Social workers, NGOs and FBOs among others should be fully involved in rehabilitation of inmates.

- Further studies can be carried out on assessment of the non-governmental organisations in rehabilitation of prison inmates.

\section{Conclusion}

The study examined the effectiveness of rehabilitation programmes in the prisons. It was discovered that the rehabilitation programmes were not very successful due to lack of fund, inadequacy of rehabilitation equipment, lack of trained personnel, lack of manpower and poor management of rehabilitation programmes among others. The findings show that prisons have not successfully achieved their objective according to the Nigerian Prison Act of 200) which is to reform and rehabilitate offenders to be good and useful citizens. Therefore, rehabilitation programmes in the prisons are not very effective.

\section{References}

Adelaja, A. (2009). State of Nigerian Prisons. Retrieved November 3, 2009, from http://234next. com/csp/cms/sites/Next/Home/5250407146/story.csp.

Amnesty International Researchers (2007). Nigeria: Amnesty International delegates say prison conditions appalling. Retrieved November 4, 2009, from http://www.amnesty.org/en/library/ asset/AFR44/019/2007/en/ac0e7770-d370-11dd-a329-2f46302a 8cc6/afr440192007en.pdf.

Ayodele,T. (1993, May 23). The Prison in Nigeria. Daily Guardian, pp. 17-19.

Civil Liberty Organisation. (1993). Annual report on human rights in Nigeria: 1 (13), 1 - 6.

Dambazau, A.B. (2007). Criminology and Criminal Justice (2nd ed.). Kaduna: Nigeria Defence Academy Press.

Dinitz, C. \& Dine, V.C. (1989). Restraining the wicked: The Dangerous offender project. Toronto: Liberty of Congress Press.

History of Enugu State. Retrieved March 14, 2012 from http://www.enugustate.gov.ng/about.php.

History of Imo State. Retrieved July 09, 2012 from http://www.imostate.gov.ng.

Igbo, E.U.M. (2007). Introduction to Criminology. Nsukka: University of Nigeria Press Ltd.

Inciardi, J.A. (2009). Criminal Justice (8th ed). New York: McGraw Hill Higher Education.

Investigating Human Rights. (n.d). Research Report: volume three. Retrieved December 7, 2009, from http://www.nigerianmuse.com/ nigeriawatch/oputavolumethree.pdf.

Latessa, E. \& Allen, H.E (1999). Corrections in the community (2nd ed.). Cincinnati, OH: Anderson Publishing co.

Nigeria Prisons Service (2000). Nigeria Prisons Service Annual Report (Lagos).

Nigerian Prisons Service. (2009). About the Nigerian prisons services. Retrieved November 26, 2009, from http://www.prisons.gov. ng/about.php.

Tan, N. (2008). Rehabilitation versus Retribution. Retrieved November 22, 2008 from the classical school. (2005). The classical school: Biological and psychological factors. Retrieved November 3, 2009, from http://www.criminality.fsu.edu/crimtheory/ week3.htm.

Udutchay, H. (2010, June 23). Transforming Nigerian Prisons. Champion Newspaper, p. 7.

Ugwuoke, C.U. (1994). Recidivism in Nigerian Prisons: A case study of Enugu Prison. M.Sc thesis, Department of Sociology/ Anthropology. University of Nigeria, Nsukka.

Ugwuoke, C.U. (2000). The dilemma of the Nigerian prisons' service: Implications for criminal justice delivery system in Nigeria. In N.G. Egbue (Ed). Journal of Sociology (50 - 59). Awka: Nnamdi Azikiwe University.

Wikipedia. (2009). Rehabilitation: Penology. Retrieved February 15, 2009, from http://en.wikipedia .org/wiki/rehabilitation.penology. 